\title{
Effects of Dopamine D2/D3 Blockade on Human Sensory and Sensorimotor Gating in Initially Antipsychotic-Naive, First-Episode Schizophrenia Patients
}

\author{
Signe Düring ${ }^{* 1,2,3}$, Birte Y Glenth $\varnothing \mathbf{j}^{1,2,3}$, Gitte Saltoft Andersen ${ }^{1,2}$ and Bob Oranje $e^{1,2,3}$ \\ 'Center for Neuropsychiatric Schizophrenia Research (CNSR), Copenhagen University Hospital, Psychiatric Center Glostrup, Copenhagen, \\ Denmark; ${ }^{2}$ Center for Clinical Intervention and Neuropsychiatric Schizophrenia Research (CINS), Copenhagen University Hospital, Psychiatric \\ Center Glostrup, Copenhagen, Denmark; ${ }^{3}$ Faculty of Health Sciences, Department of Neurology, Psychiatry, and Sensory Sciences, University of \\ Copenhagen, Copenhagen, Denmark
}

It has been suggested that psychophysiological measures of sensory and sensorimotor gating, P50 gating and prepulse inhibition of the startle reflex (PPI), underlie core features of schizophrenia and are linked to dopaminergic pathways in the striatum and prefrontal cortex. In the present study, the effects of a potent D2/D3 receptor antagonist, amisulpride, were investigated on PPI and P50 gating in a large sample of antipsychotic-naive, first-episode patients with schizophrenia. A total of 52 initially antipsychotic-naive, first-episode schizophrenia patients were assessed for their P50 gating, PPI, and habituation/sensitization abilities at baseline and after 2 and 6 weeks of treatment with flexible doses of amisulpride. In addition, 47 matched healthy controls were assessed at baseline and after 6 weeks. At baseline, the patients showed significantly reduced PPI, yet normal levels of P50 gating, habituation, and sensitization. Treatment with amisulpride showed no effects on these measures, either at 2 or 6 weeks of follow-up. This is the first study investigating the effects of monotherapy with a relatively selective dopamine D2/D3 receptor antagonist (amisulpride) on sensory and sensorimotor gating deficits in a longitudinal study of a large group of initially antipsychotic-naive, first-episode patients with schizophrenia. Our finding that amisulpride effectively reduced symptom severity in our patients without reducing their PPI deficits indicates that increased activity of dopamine D2 receptors may be involved in symptomatology of patients with schizophrenia, but not in their sensorimotor gating deficits. Neuropsychopharmacology (2014) 39, 3000-3008; doi:I0.1038/npp.2014.I52; published online 6 August 2014

\section{INTRODUCTION}

Since the early 1980s, both sensory and sensorimotor gating have been consistently reported to be impaired in patients with schizophrenia (Braff et al, 1978; Swerdlow et al, 2007; Mackeprang et al, 2002; Oranje et al, 2013). It is widely believed that both these gating phenomena can be assessed with electrophysiology, that is, by the so-called prepulse inhibition of the startle reflex paradigm (PPI) and the P50 suppression paradigm.

PPI is usually assessed by an auditory paradigm: trials with a loud stimulus are interchanged with trials in which the same loud stimulus is preceded by a less intense prestimulus. In healthy subjects, the loud stimulus typically triggers a startle reflex that is normally reduced when this loud stimulus is preceded by a prepulse within a certain (30-500 ms) time interval (Aasen et al, 2005; Braff et al,

\footnotetext{
* Correspondence: Dr S Düring, Center for Neuropsychiatric Schizophrenia Research, Copenhagen University Hospital, University Psychiatric Center Glostrup, Ndr. Ringvej 29-67, DK-2600 Glostrup, Denmark, Tel: +45 386 40828, Fax: +45 432 34653, E-mail: Signe@cnsr.dk Received 27 December 2013; revised I 5 June 2014; accepted 16 June 2014; accepted article preview online 23 June 2014
}

2001). As the startle reflex is usually assessed with electromyography, it is considered a measure of sensorimotor gating.

In typical assessment of P50 suppression, a weak intensity auditory stimulus is repeated twice over a short period of time (usually $500 \mathrm{~ms}$ ). The first stimulus normally triggers a positive deflection after $50 \mathrm{~ms}$ in the electroencephalography (EEG) recordings of healthy subjects, whereas this response is reduced to the second stimulus. Patients suffering from schizophrenia have shown both significantly reduced PPI and P50 suppression, irrespective of medication status (Aggernaes et al, 2010; Oranje et al, 2013; Quednow et al, 2006; Wynn et al, 2007), disease duration, and acute status (Perry et al, 2002).

In particular, the influence of the dopamine D2 receptor on gating paradigms has been studied, because blocking this receptor reduces (predominantly positive) symptomatology in schizophrenia patients. However, the majority of these studies had cross-sectional designs. In the first longitudinal study on antipsychotic-drug naive, first-episode patients with schizophrenia, our research group found that neither the first-generation antipsychotic compound (FGA), zuclopenthixol, nor the second-generation antipsychotic compound (SGA), risperidone, normalized the patients' 
impaired sensorimotor gating (Mackeprang et al, 2002). There is some evidence suggesting that SGAs alleviate PPI deficits more than FGAs (Kumari and Sharma, 2002; Kumari et al, 2002; Aggernaes et al, 2010), although most of these studies were cross-sectional in design. Interestingly, Csomor et al (2008) found that haloperidol increased PPI and P50 suppression in healthy individuals with initial low levels, yet decreased it in healthy individuals with initial high levels of these measures. Recently, Volter et al (2012) observed an association of the DRD2 single-nucleotide polymorphism (SNP) rs1800497 with PPI in two independent samples of healthy individuals. In spite of these studies in healthy volunteers, it is currently uncertain whether D2 receptors are involved in gating deficits of patients with schizophrenia. The antipsychotic compounds, and their effect on these measures, that have been investigated in first-episode patients so far were not selective for this specific receptor subtype.

In the present study, we examined the effects of the selective dopamine D2/D3 receptor antagonist, amisulpride, on sensory and sensorimotor deficits, as well as habituation and sensitization, in a large cohort of antipsychotic-naive, first-episode patients with schizophrenia. As patients score usually low levels of PPI and P50 suppression, in combination with the above-mentioned report that haloperidol increases these levels in healthy yet low-scoring individuals (Csomor et al, 2008), we expected amisulpride to ameliorate these deficits in our patients as well.

\section{PATIENTS AND METHODS}

\section{Subjects}

The study was approved by the Ethical Committee of the Capital Region Copenhagen (Registration: HD-2008-088). The study was part of the Pan European Collaboration Antipsychotic-Naive Studies (PECANS) (Nielsen et al, 2012a, b).

Written and oral information was given to the patients, and all patients signed informed consent. A total of 61 firstepisode, antipsychotic-naive schizophrenia patients between 18 and 41 years of age, and 47 controls matched on sex, age, and parental socioeconomic status were recruited for the study (see Table 1). The patients were referred from psychiatric centers in the Capital Region of Copenhagen, and completed the Schedule of Clinical Assessment, version 2.1 (SCAN; Wing et al, 1990) performed by a trained physician (SD) and nurse (GSA). All included patients met the ICD-10 criteria for schizophrenia. Controls were recruited from the community. Participation was only offered to control subjects with no previous mental health issues and no known first-degree relatives with mental health disorders. All subjects were examined physically to exclude somatic illness.

The severity of psychopathological symptoms was assessed by the PANSS interview (positive and negative syndrome scale) (Kay et al, 1988). Exclusion criteria were previous impact-related unconsciousness, organic brain damage or disease, intellectual disability (IQ <70), diseases or processes contraindicated with amisulpride treatment (allergy, prolactin-producing tumor, and so on), and all patients treated involuntarily or under judicial ruling.
Substance use and abuse were not exclusion criteria, but their extent and type were noted.

At baseline, 52 patients completed P50 testing, and 51 completed PPI testing. All subjects were reassessed after 6 weeks, while patients were additionally reassessed after 2 weeks following the baseline assessment. Predominant dropout reasons were discomfort during the baseline assessment, insufficient treatment effect, and/or worsening of symptoms (see flowchart, Table 1).

Between baseline and follow-up, patients were treated with amisulpride dosages according to their clinical needs (50-800 mg/day, mean 288 (SD 170)), and no antidepressants or other antipsychotics were taken throughout the treatment period of the study. However, some patients were prescribed a short-acting benzodiazepine (Oxazepam) on an 'if needed basis', with the request not to take it from $2300 \mathrm{~h}$ before a test day. Nevertheless, and as a result, urine tests on benzodiazepines were positive for two patients at baseline, and four at follow-up. One patient was prescribed painkillers, and therefore tested positive for opiates at 6week follow-up. In addition, one patient at baseline tested positive for cannabis.

\section{Psychophysiology}

Neither the patients nor the healthy controls had ever participated in psychophysiological research before. All subjects were examined with the Copenhagen Psychophysiology Test Battery (CPTB) (Oranje and Glenthoj, 2013; Jensen et al, 2008; Wienberg et al, 2010). The CPTB includes PPI, P50 suppression, mismatch negativity (MMN), and selective attention paradigms. Tests are always assessed in this fixed order. To keep this report focused, only results on PPI, P50 suppression, habituation, and sensitization are presented. The psychophysiological tests were assessed between $0900 \mathrm{~h}$ and $1200 \mathrm{~h}$. To avoid acute and/or withdrawal effects of nicotine, smoking was not allowed from $1 \mathrm{~h}$ before testing (Braff et al, 2001). All subjects were requested not to drink any caffeinated beverages on a test day until all tests were completed.

\section{Signal Recording}

EEG as well as electromyography (EMG) recordings were performed with BioSemi hardware (Amsterdam, The Netherlands) using a cap with 64 active electrodes. The eye-blink component of the acoustic startle response was measured by recording electromyography activity from the right $\mathrm{m}$. orbicularis oculi. Two electrodes were placed under the right eye for startle response measurement. The first of these was aligned with the pupil, the other positioned just laterally. BESA software (version 5.2.4, MEGIS Software, Gräfelfing, Germany) was used for further processing of the data.

\section{Paradigms}

Both PPI and P50 gating paradigms have been described previously (Oranje et al, 2013; Jensen et al, 2007). Briefly, all auditory stimuli were presented by a computer running Presentation (Neurobehavioral Systems, Albany, NY) software and were presented binaurally through stereo 
Table I Flow of Patients in the Study

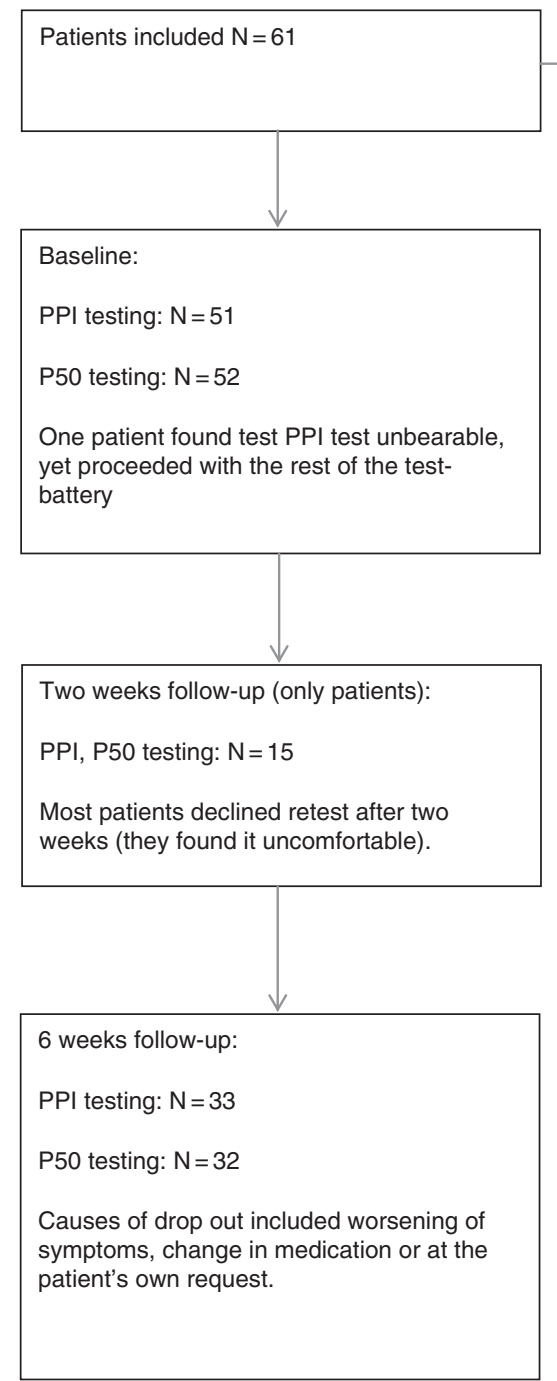

Patients excluded prior to baseline CPTB testing: $\mathrm{N}=9$, main reasons were related to severity of symptoms and the inability to wait treatment, or patients declined after initial acceptance insert earphones (Eartone-ABR, C and $\mathrm{H}$ Distributors, Milwaukee, WI).

Habituation, sensitization, and PPI. Subjects were seated in a comfortable armchair in a room with a sound level below $40 \mathrm{~dB}$. They were instructed to avoid unnecessary movements, keep their eyes fixed on a spot on the wall directly in front of them, and stay awake. Assessment of PPI and habituation started with $5 \mathrm{~min}$ of acclimation to background noise ( $70 \mathrm{dBa}$ white noise), after which three experimental blocks of stimuli were superimposed on the background noise.

Blocks 1 and 3 were used to assess habituation of the acoustic startle reflex. The two blocks were identical and consisted of eight pulse-alone trials (white noise with an intensity of $115 \mathrm{dBa}$, and duration of $20 \mathrm{~ms}$, instant rise and fall) with randomized intertrial intervals between 10 and $20 \mathrm{~s}$. Block 2 consisted of 50 trials presented in a pseudorandomized order to assess PPI. Because prepulse intensity and interstimulus intervals (ISI) can affect levels of PPI (Braff et al, 2001), our paradigm contained two levels of each; prepulse intensities of 6 and $15 \mathrm{~dB}$ (white noise, $20 \mathrm{~ms}$ in duration) above background and stimulus onset asynchronies (SOAs) of 60 and $120 \mathrm{~ms}$. The intertrial intervals were randomized between 10 and $20 \mathrm{~s}$. Randomized across the session, 10 pulse-alone and 10 of each prepulse-pulse combination $(60 \mathrm{~ms} / 76 \mathrm{dBa}, 60 \mathrm{~ms} / 85 \mathrm{dBa}, 120 \mathrm{~ms} / 76 \mathrm{dBa}$, and $120 \mathrm{~ms} / 85 \mathrm{dBa}$ ) were presented.

Following offline filtering of the data between 25 and $250 \mathrm{~Hz}$, startle amplitude was scored as the highest absolute amplitude in the time interval $20-100 \mathrm{~ms}$ after the startle eliciting pulse, whereas PPI was expressed as: $((1-)(\mathrm{PP} /$ $\mathrm{PA})) \times 100 \%$ ), where $\mathrm{PP}$ is average startle amplitude to prepulse-pulse trials and PA is average amplitude to pulsealone trials.

Sensitization was defined as the increase in startle amplitude from the first to the second trial in the first 
habituation block. Please note that because of retest effects, sensitization could only be assessed at baseline (Aggernaes et al, 2010). Habituation was defined as the percentage decrease in average startle amplitude from block 1 to block 3 .

P50 suppression. P50 gating was assessed in three experimental blocks, each consisting of 40 pairs of bursts $(1.5 \mathrm{~ms}$ and $80 \mathrm{~dB})$ of white noise, with an instantaneous rise time, an ISI of $500 \mathrm{~ms}$, and a fixed intertrial interval of $10 \mathrm{~s}$. Processing of the data started with correction for eye movement by applying the surrogate model of BESA. Correction of movement and other nonparadigm-related artifacts were subsequently performed by removing those epochs from the database in which maximum and minimum amplitude differences exceeded $150 \mu \mathrm{V}$. Averaged epochs were then filtered between 1.6 and $70 \mathrm{~Hz}$. P50 amplitudes were scored from $\mathrm{Cz}$ with average reference, and were defined as the largest trough-to-peak amplitude within an interval of 40$90 \mathrm{~ms}$ following the first (conditioning or ' $\mathrm{C}$ ') stimulus in each paired click. The P50 amplitude following the second (testing or ' $\mathrm{T}$ ') stimulus was identified as the largest troughto-peak amplitude within an interval of $\pm 10 \mathrm{~ms}$ of the latency of the maximum P50 amplitude to the $\mathrm{C}$ stimulus. P50 suppression was expressed as the ratio 'T/C.'

Statistical analyses. All analyses were performed with SPSS version 21.00 (SPSS, USA). In accordance with other studies (Cadenhead et al, 1997; Kumari et al, 2004; Kumari 2011; Hetrick et al, 1996), we found sex to influence some of our data (both PPI and P50 suppression data, see Results). Age and smoking (yes/no) did not covary significantly in any of the tests.

Although raw startle amplitude, habituation, and sensitization data were normally distributed, this was not the case for all PPI data. Therefore, only PPI tests for which no suitable nonparametric alternative was available were performed parametrically. All others were performed nonparametrically. Raw startle amplitude was analyzed with repeated measures ANOVA with between-factors 'time' (baseline vs 6 weeks) and 'group' (controls $v s$ patients) and withinfactor 'stimulus' (pulse-alone and the four prepulse-pulse combinations). Group effects in PPI were analyzed by ANOVA with between-factor 'group' and within-factors 'time' (baseline vs 6 weeks), 'prepulse intensity' ( $85 / 76 \mathrm{dBa})$, and 'SOA' $(60 / 120 \mathrm{~ms})$. We further tested whether there were group differences in PPI at baseline (because of the larger data set at baseline) with between-factor 'group' and within-factors 'prepulse intensity' and 'SOA'. Post hoc, we analyzed the effect of time (which equals treatment in patients) for each group separately with repeated measures ANOVA with factors 'time' (baseline vs 6 weeks, for patients also baseline $v s$ two weeks), 'prepulse intensity', and 'SOA'.

Habituation was analyzed by repeated measures ANOVA with within-factor 'time' (baseline vs 6 weeks) and between-factor 'group'. Sensitization was analyzed with repeated measures ANOVA with between-factor 'group' and within-factor 'trial' (amplitude trial $1 v s$ amplitude trial 2 of block 1).

P50 suppression data were analyzed nonparametrically, except for the group by time analyses. Raw P50 amplitude data were analyzed by repeated measures ANOVA with between-factor 'group' and within-factors 'time' and 'stimulus' (average amplitude to $\mathrm{C} v s \mathrm{~T}$ stimuli). Similarly, P50 suppression was analyzed by repeated measures ANOVA with between-factor 'group' and within-factor 'time'. In addition, we tested for group differences in P50 suppression at baseline because of the larger data set (Mann-Whitney test).

The effect of amisulpride on psychopathology (PANSS positive, negative, general, and total scores) and functioning (GAF score) was analyzed with paired samples Student's $t$-tests (baseline to 6 weeks).

The relation between PPI, P50 suppression, dose of medication, symptomatology, and functioning scores were investigated with either Pearson's or Spearman's correlation tests, depending on the distribution of the data.

\section{RESULTS}

\section{General}

The groups of patients and controls neither differed in age nor sex composition. The patients were moderately to severely ill as can be inferred from their PANSS score and were treated with low to moderate doses of amisulpride (Table 2). The patients who dropped out of the study neither differed significantly in PPI $(P$-value range $0.075-$ $1.0)$ or $P 50$ suppression $(0.389, P=0.53)$ levels nor in PANSS scores (total, general, positive, or negative scores, $P$-value range $0.061-0.58)$ from patients who completed the study. As mentioned above, the urine samples of some patients tested positive for other compounds than amisulpride; none of the below-reported statistical outcomes changed significance upon inclusion or exclusion of these subjects from the analyses.

\section{PPI}

Analysis of the raw startle amplitude data showed a significant effect of trial type $(\mathrm{F}(4,64)=6.97, \quad P<0.001$,

Table 2 Demographics, PANSS Scores, and Medication

\begin{tabular}{|c|c|c|c|}
\hline & Controls & Patients & Controls Patients \\
\hline & \multicolumn{2}{|c|}{ Baseline } & $\begin{array}{l}\text { Follow-up } \\
\text { at } 6 \text { weeks }\end{array}$ \\
\hline $\begin{array}{l}\text { Subjects }(N) \\
\text { (male/female) }\end{array}$ & $47(30 / 17)$ & $52(34 / 18)$ & $43(30 / 13) 33(23 / 10)$ \\
\hline Mean age (SD) & $25.8(6.4)$ & $24.9(6.1)$ & \\
\hline \multicolumn{4}{|l|}{ Average PANSS scores (SD) } \\
\hline Positive & & 20.1 (SD 3.8) & I 4.35 (SD 4.0)* \\
\hline Negative & & 21.4 (SD 7.2) & 19.38 (SD 6.0) \\
\hline General & & $42.6(\mathrm{SD} 8.9)$ & $31.48(\mathrm{SD} 8.5)^{*}$ \\
\hline Total & & 84.I (SD I5.8) & 65.20 (SD | 5.3 )* \\
\hline GAF score total & & 40.7 (SD 9.1) & 50.7 (SD | 4.4)* \\
\hline Mean dosage medication & & & $288.46(169.9)$ \\
\hline
\end{tabular}

*Significantly decreased compared with baseline $(P<0.05)$. 
Table 3 PPI: Average Raw Startle Amplitudes for Patients and Controls

\begin{tabular}{|c|c|c|c|c|c|}
\hline \multirow[t]{2}{*}{ Trial type } & \multicolumn{2}{|c|}{ Baseline, amplitudes in $\mu \mathrm{V}$ (SEM) } & \multirow{2}{*}{$\begin{array}{c}\begin{array}{c}\text { 2-Week follow-up, } \\
\text { amplitudes in } \mu \mathrm{V} \text { (SEM) }\end{array} \\
\text { Patients }\end{array}$} & \multicolumn{2}{|c|}{ 6-Week follow-up, amplitudes in $\mu \vee$ (SEM) } \\
\hline & Patients & Controls & & Patients & Controls \\
\hline PA (pulse alone) & $153.8(16.2)$ & $134.9(\mid 5.2)$ & $177.9(44.8)$ & I55.5 (|7.9) & $123.7(16.9)$ \\
\hline $85 / 120$ & $69.9(10.2)$ & $51.3(10.8)$ & $78.5(25.9)$ & $86.5(15.5)$ & $54.3(14.1)$ \\
\hline $85 / 60$ & $69.4(9.0)$ & $52.6(9.9)$ & $81.3(26.8)$ & $80.0(15.6)$ & $47.5(8.3)$ \\
\hline $76 / 60$ & I $10.6(14.5)$ & $78.5(13.3)$ & $122.4(39.0)$ & I I8.| (19.0) & $73.3(12.4)$ \\
\hline
\end{tabular}

$\eta^{2}=0.30$ ), indicating significantly reduced amplitudes in prepulse-pulse trials compared with pulse-alone trials. We found no effect of time $\left(\mathrm{F}(1,67)=0.54, P=0.46, \eta^{2}=\right.$ $0.008)$, group $\left(\mathrm{F}(1,67)=3.42, P=0.069, \eta^{2}=0.049\right)$, or an interaction effect between time and group $(\mathrm{F}(1,67)=1.02$, $P=0.32, \eta^{2}=0.015$; Table 3$)$.

The main analysis of the (percentage) PPI data (baseline to follow-up) showed a significant main effect of group $\left.\mathrm{F}(1,67)=4.64, P=0.035, \eta^{2}=0.065\right)$, indicating lower PPI across all four trial types in patients compared with controls, regardless of time (treatment). In addition, a significant main effect of prepulse intensity $(\mathrm{F}(1,67)=22.91$, $\left.P<0.001, \eta^{2}=0.26\right)$ was found, indicating significantly higher percentage PPI in the high-intensity prepulse trials, regardless of group. Furthermore, a significant sex $\times$ time interaction was found $\left(\mathrm{F}(1,67)=4.35, \quad P=0.041, \eta^{2}=\right.$ 0.061 ), whereas a main effect of sex reached trend level of significance $\left(\mathrm{F}(1,67)=3.56, P=0.063, \eta^{2}=0.05\right.$; the effect of sex was even more pronounced in the follow-up data $\left.\left(\mathrm{F}(1,70)=7.91, P=0.006, \eta^{2}=0.10\right)\right)$. No interaction effect between time and group $\left(\mathrm{F}(1,67)=1.47, P=0.23, \eta^{2}=\right.$ 0.021) was found. As expected from the main analysis, no differences in percentage PPI were found between baseline and follow-up in either patients (6-week followup: $\left(\mathrm{F}(1,30)=0.91, P=0.35, \eta^{2}=0.029\right), 2$-week followup: $\left.\left(\mathrm{F}(1,12)=0.009, \quad P=0.92, \eta^{2}=0.001\right)\right)$ or controls $\left.\left(\mathrm{F}(1,37)=1.08, \quad P=0.31, \quad \eta^{2}=0.029\right)\right)$. To confirm that amisulpride indeed had no influence on PPI, we subsequently performed nonparametric (Wilcoxon) tests. No significant difference between baseline and 6-week followup $(P>0.12, d<0.27)$ was found, in spite of the fact that the average PPI of the patients decreased in all trial types. Similarly, the more acute effects of amisulpride on PPI, from baseline to 2-week follow-up, reached no statistical significance $(P>0.36, d<0.26)$ except in the $76 / 120$ trials, where PPI improved significantly $(z=2.67, P=0.008$, $d=0.86$; see also Figure 1 ).

At baseline, a main effect of group was also found in the larger population, although only at trend level of significance $\left(\mathrm{F}(1,90)=3.70, P=0.056, \eta^{2}=0.04\right)$. This indicates, similarly to the main analysis, that patients scored lower PPI than controls. This was confirmed in nonparametric analyses where patients scored significantly lower PPI in all trial types $(85 / 120: z=2.27, P=0.023, d=0.31 ; 85 / 60$ : $z=2.26, \quad P=0.023, \quad d=0.28 ; 76 / 120: \quad z=2.52, \quad P=0.012$, $d=0.52 ; 76 / 60: z=2.01, P=0.045, d=0.28)$. These group

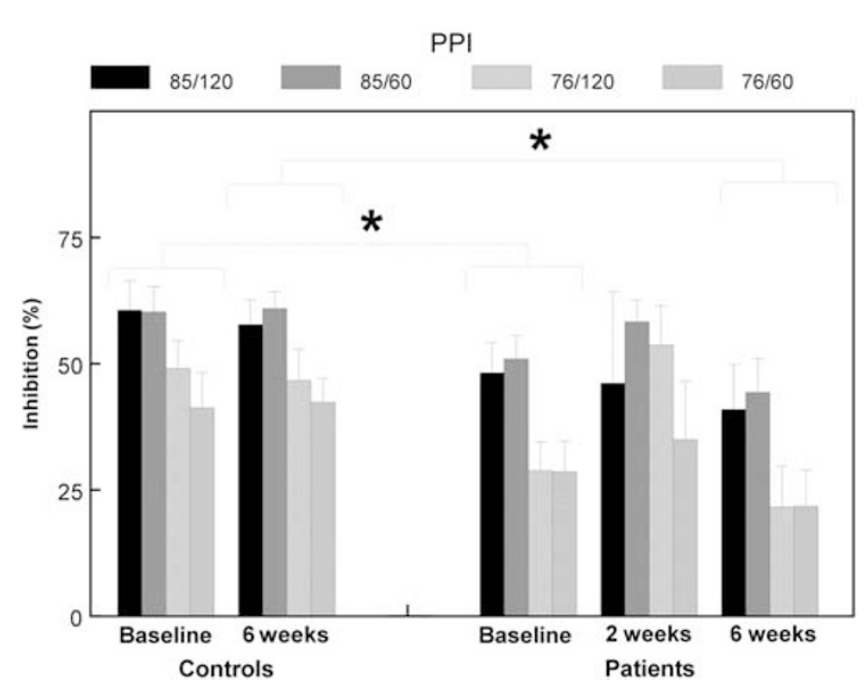

Figure I Percentage PPI for both patients and controls specified for all assessments and trial types, showing significance (*) less PPI for patients compared with controls at baseline as well as at 6 weeks of follow-up.

differences appeared based on a significantly increased amplitude to prepulse-pulse stimuli in patients compared with controls (85/120: $z=2.37, P=0.018, d=0.26$; 85/60: $z=1.97, \quad P=0.049, d=0.26 ; 76 / 120: \quad z=2.45, \quad P=0.014$, $d=0.32 ; 76 / 60: z=1.69, P=0.091$ n.s., $d=0.33$ ), and not based on a difference in pulse-alone trials $(z=0.21, P=0.83$ n.s., $d=0.09$ ).

\section{Habituation and Sensitization}

The repeated measures ANOVA on habituation showed no effect of time $\left(\mathrm{F}(1,68)=0.048, P=0.83, \eta^{2}=0.001\right)$ or of group $\left(\mathrm{F}(1,68)=0.037, P=0.85, \eta^{2}=0.001\right)$ or an interaction effect between time and group $(\mathrm{F}(1,68)=0.045$, $\left.P=0.83, \eta^{2}=0.001\right)$.

The repeated measures ANOVA on sensitization showed neither a significant increase in amplitude from trial 1 to trial 2 of habituation block 1 (ie, no sensitization; $\left(\mathrm{F}(1,91)=0.123, P=0.73, \eta^{2}=0.001\right)$ nor a main effect of group $\left(\mathrm{F}(1,91)=0.21, P=0.88, \eta^{2}<0.001\right)$ nor an interaction effect $\left(\mathrm{F}(1,91)=0.12, \quad P=0.73, \quad \eta^{2}=0.001 ; \quad\right.$ see Figure 2). 

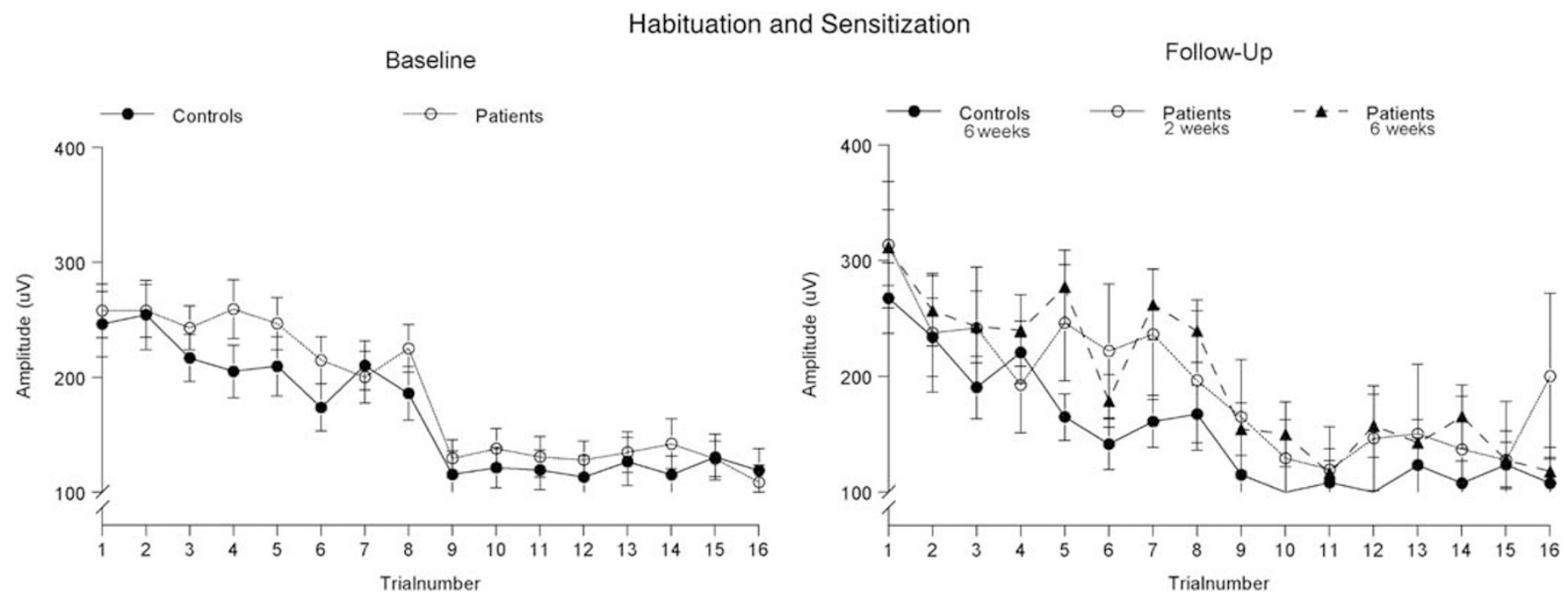

Figure 2 Average startle amplitude to the pulse-alone trials of blocks I and 3, showing neither a significant effect of group nor of treatment. Please note that sensitization is defined as the increase in amplitude from trial I to trial 2, whereas habituation is defined as the percentage drop in average amplitude between the trials of blocks I and 3.
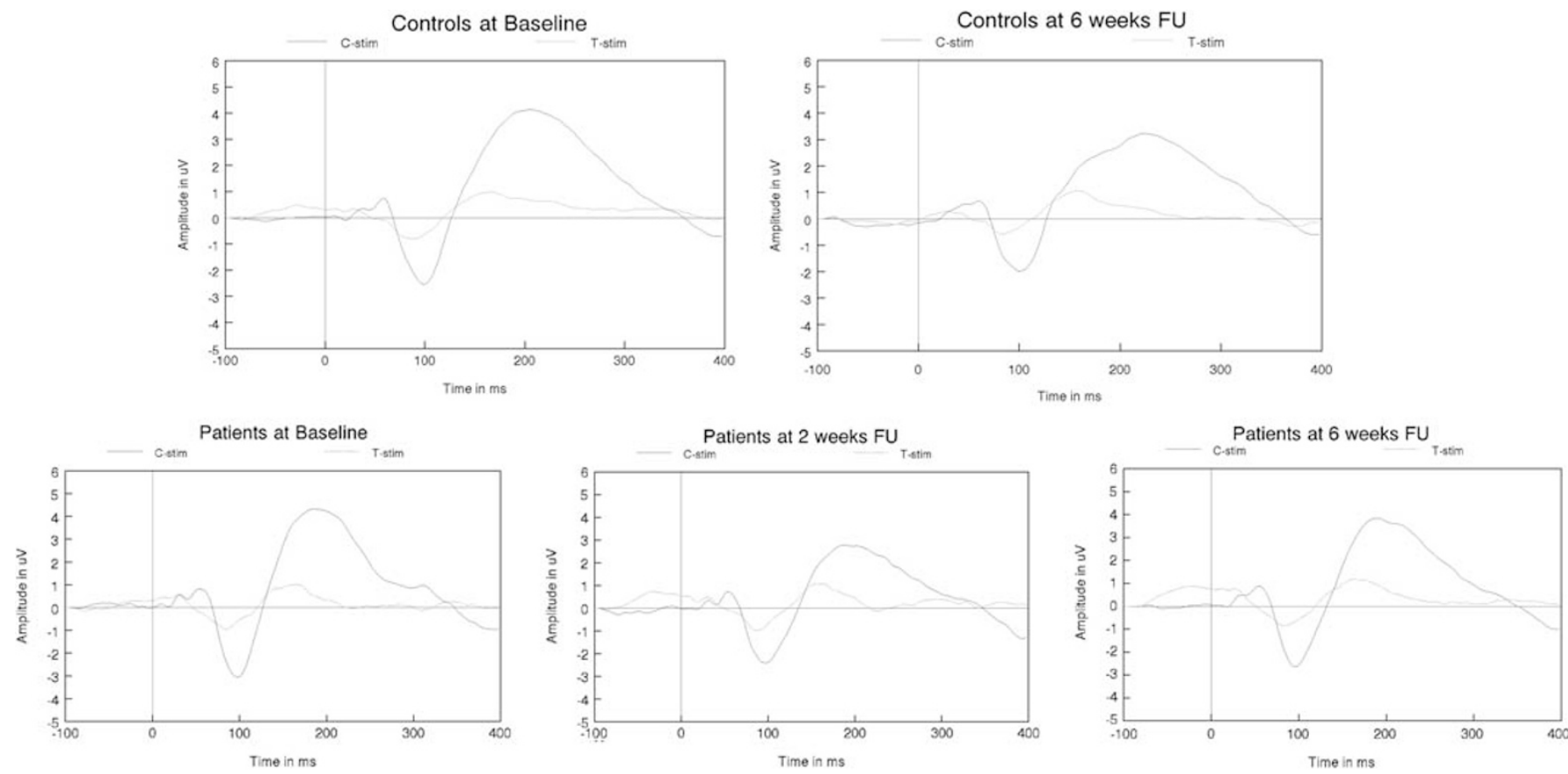

Figure 3 Grand average ERPs to $C$ and T stimuli for both patients and controls specified for all assessments, showing neither significant group differences nor significant effects of treatment FU, follow-up.

\section{P50}

The analysis of the raw amplitude data showed a significant main effect of stimulus only $(\mathrm{F}(1,69)=5.16, P=0.026$, $\left.\eta^{2}=0.070\right)$, indicating the usual drop in amplitude to $\mathrm{T}$ stimuli, compared with $\mathrm{C}$ stimuli, regardless of group. No significant main effects of time $(\mathrm{F}(1,69)=3.69$, $\left.P=0.55, \quad \eta^{2}=0.005\right)$, group $(\mathrm{F}(1,69)=0.095, \quad P=0.76$, $\left.\eta^{2}=0.001\right)$, or an interaction effect between time and group
$\left(\mathrm{F}(1,69)=0.572, \quad P=0.45, \quad \eta^{2}=0.008\right)$ were found (see Figure 3 and Table 4).

Similar to the raw amplitude data, analysis of the P50 suppression data (T/C ratio) showed only a main effect of sex $\left.\mathrm{F}(1,69)=6.47, P=0.013, \eta^{2}=0.086\right)$; no main effects of time $\left(\mathrm{F}(1,69)=0.29, \quad P=0.591, \quad \eta^{2}=0.004\right)$ or group $(\mathrm{F}(1,69)=0.824, P=0.37)$, or an interaction effect between time and group $\left.\mathrm{F}(1,69)=0.824, P=0.37, \eta^{2}=0.012\right)$ were found. The T/C score did not differ significantly between 
Table 4 P50 Data: Average P50 Suppression Data for Patients and Controls

\begin{tabular}{|c|c|c|c|c|c|}
\hline \multirow[t]{2}{*}{ Stimuli } & \multicolumn{2}{|c|}{ Baseline, amplitudes in $\mu \mathbf{V}$ (SEM) } & \multirow{2}{*}{$\frac{\text { 2-Week follow-up, amplitudes in } \mu V \text { (SEM) }}{\text { Patients }}$} & \multicolumn{2}{|c|}{ 6-Week follow-up, amplitudes in $\mu \vee$ (SEM) } \\
\hline & Patients & Controls & & Patients & Controls \\
\hline T stimulus & $0.45(0.08)$ & $0.52(0.08)$ & $0.40(0.14)$ & $0.27(0.07)$ & $0.36(0.08)$ \\
\hline $\mathrm{T} / \mathrm{C}$ & $0.31(0.06)$ & $0.29(0.04)$ & $0.38(0.17)$ & $0.19(0.04)$ & $0.22(0.04)$ \\
\hline
\end{tabular}

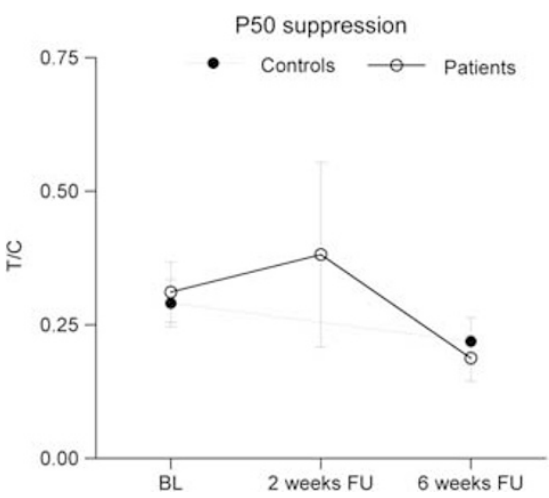

Figure 4 P50 suppression (T/C) for patients and controls showing neither significant group differences nor significant effects of treatment. BL, baseline; FU, follow-up.

baseline and 2-week follow-up in the patients $(z=1.098$, $P=0.27, d=0.06$ ), nor did it differ between the larger population of patients and controls at baseline $(z=0.183$, $P=0.86, d=0.29$; see Figure 4$)$.

\section{Psychopathology and Daily Functions}

A statistically significant drop in PANSS positive, general, and total scores, but not in PANSS negative score, was found between baseline and 6-week follow-up. Furthermore, the patients' GAF score increased significantly in this same period of time (see Table 2).

\section{Correlations}

We found no significant correlation between baseline PPI measures and ratings of psychopathology (PANSS positive, negative, general, or total score), daily functioning (GAF), or dosage of amisulpride at 6-week follow-up. In the baseline data we found a significant correlation between P50 suppression score and PANSS general $\left(r_{\mathrm{S}}=0.42, P=0.004\right)$ as well as PANSS total scores $\left(r_{\mathrm{S}}=0.31, P=0.037\right)$, although this last correlation disappeared after controlling for the PANSS general score. P50 suppression did not correlate with the GAF score; neither did it correlate with any of the PPI measures. PPI in patients correlated significantly between baseline and 6-week follow-up $\left(0.43<r_{\mathrm{S}}<0.75\right)$ in all trial types; however, between baseline and 2-week followup only the $85 / 60\left(r_{\mathrm{S}}<0.59\right)$ and $76 / 120\left(r_{\mathrm{S}}<0.64\right)$ trials correlated significantly. Similarly, PPI in controls correlated significantly between baseline and 6-week follow-up, although in higher levels $\left(0.51<r_{\mathrm{S}}<0.92\right)$ compared with patients and in all trial types. Levels of P50 suppression between baseline and follow-up correlated $\left(r_{\mathrm{S}}=0.42\right)$ in controls only, and not in patients $\left(r_{\mathrm{S}}<0.26\right)$.

\section{DISCUSSION}

This is the first study investigating the effects of a selective dopamine D2/D3 antagonist (amisulpride) on sensory and sensorimotor gating deficits in a large group of initially antipsychotic-naive, first-episode patients with schizophrenia. At baseline, patients showed significantly reduced percentage PPI compared with controls, and this was not diminished after 6 weeks of amisulpride treatment. Unexpectedly, patients showed neither P50 gating deficits at baseline nor at follow-up compared with controls. Similarly, habituation and sensitization showed no statistically significant group differences at baseline and follow-up.

Our patients showed significantly less PPI compared with controls at both baseline and follow-up. In addition, they showed no significant change in PPI between baseline and follow-up, except for a transient increase in PPI in the $76 / 120$ trial types at 2-week follow-up. This indicates that amisulpride did not ameliorate PPI deficits in our patients, despite effectively reducing their symptoms (except their negative symptoms) and significantly improving their daily functioning (GAF score). The reduced PPI of patients at baseline is consistent with our previous results on PPI in antipsychotic-naive, first-episode schizophrenia patients (Aggernaes et al, 2010). This further substantiates that PPI deficits are already present in early stages of schizophrenia and do not occur as a result of medication or disease progress, and this provides further evidence that PPI is a useful biomarker in antipsychotic drug development (Turetsky et al, 2007). The fact that amisulpride did not alleviate our patients' PPI deficits-it even (nonsignificantly) decreased average PPI in all trial types between baseline and 6-week follow-up-indicates that blockade of D2/D3 receptors does not ameliorate sensorimotor gating deficits. This is in agreement with our previous findings showing no effect of risperidone and zuclopenthixol treatment on PPI deficits in a similar cohort of patients (Mackeprang et al, 2002), as well as to an ever-growing body of evidence showing that FGAs in general and haloperidol in specific do not alleviate PPI deficits in patients with schizophrenia (Duncan et al, 2003; Wynn et al, 2007; Oranje et al, 2002; Kumari et al, 2002), although in contrast 
to amisulpride these compounds have a rather broad receptor affinity profile in addition to their relatively strong affinity for D2 receptors. Furthermore, our data imply that the other specific characteristics of amisulpride, that is, its proposed functional limbic selectivity (Natesan et al, 2008) and differential distribution in the brain (Perrault et al, 1997; Schoemaker et al, 1997), have no beneficial effect on PPI in this particular group of patients. Taken together, blocking D2 receptors for periods longer than 6 weeks does not appear to alleviate sensorimotor gating deficits in antipsychotic-naive first-episode patients with schizophrenia, whether this is achieved with first- or secondgeneration antipsychotics. Our finding that amisulpride significantly increased PPI in one specific trial type (76/120) and following a 2-week treatment period only may however warrant further investigation: it may indicate processes that take place before receptor accommodation as a result of treatment occurs. However, this finding was only based on the small number of subjects who agreed to be retested after a period of 2 weeks, and there were no control data available at that time point.

The current P50 suppression data did not replicate our earlier results, where we found significantly less P50 suppression in our previous large cohort of antipsychoticnaive, first-episode patients with schizophrenia, using an identical P50 suppression paradigm (Oranje et al, 2013). This cannot be explained by any technical issues, as we found significant P50 suppression in both of our current experimental groups. We have no explanation for this negative result, except that the patients appeared to score slightly lower T/C ratios, whereas the controls scored slightly higher ratios than in our previous cohort (Oranje et al, 2013); this in spite of the fact that the subject characteristics between the two studies appear to be very similar: there are no major differences in age, sex composition, or in the patients' symptomatology. There are other studies in which P50 gating did not differ between patients and controls, especially in the earlier phases of the disease (de Wilde et al, 2007; Boutros et al, 1991; Arnfred et al, 2003). Similar to our previous study, however, we found a correlation between the patients' P50 suppression and PANSS general and total scores. Furthermore, consistent with literature, no association was found between P50 suppression and percentage PPI (Oranje et al, 1999; Oranje et al, 2006; Schwarzkopf et al, 1993; Braff et al, 2007).

Levels of habituation and sensitization did not differ between the groups. This adds to a growing number of other studies where these phenomena did not differ between schizophrenia patients and controls, especially in studies in first-episode patients (Aggernaes et al, 2010; Mackeprang et al, 2002; Kumari et al, 2007; Quednow et al, 2008) although not with the study of Ludewig et al (2003). Our data support the concept that habituation deficits in schizophrenia reflect subgroup characteristics or disease progress.

There are some limitations to this study. One consideration would be the long-term effects of amisulpride; the current study did not test these, and we cannot ascertain whether changes will appear later. However, we find this unlikely, as PPI scores on average tended to decrease even further following 6 weeks of amisulpride treatment rather than to improve. Another issue to consider is that amisulpride, besides having D2/D3 receptor affinity, also has considerable affinity for the serotonergic 5HT-7 receptor (Horacek et al, 2006; Abbas et al, 2009), which may explain some of our current findings.

In conclusion, we found PPI to be deficient in our large group of antipsychotic-naive, first-episode schizophrenia patients. The data further showed that blockade of dopamine D2/D3 receptors with amisulpride for a period of 6 weeks did not ameliorate these deficits. Habituation and sensitization was not affected in our patients, suggesting that these deficits may be related to disease progress or treatmentrelated issues. Quite unexpectedly however, we also found no P50 gating deficit in our patients compared with controls, and this is in contrast to other studies, including some of our own, for which we have no proper explanation.

\section{FUNDING AND DISCLOSURE}

The authors declare no conflict of interest.

\section{ACKNOWLEDGEMENTS}

We recognize the valuable work of the research assistants Katharina Alfsen (CRN) and Mikkel Erlang Sørensen (MSc) as well as of research secretary Lisbeth Jensen from the Center for Neuropsychiatric Schizophrenia Research (CNSR) and Center for Clinical Intervention and Neuropsychiatric Schizophrenia Research (CINS) for assisting in the recruitment and assessment of participants. This study was sponsored by the University of Copenhagen, Faculty of Health and Medical Sciences (211-0747/10-3012), Psychiatry of the Capital Region of Copenhagen, and CINS (Lundbeck Foundation Center for clinical Intervention and Neuropsychiatric Research, R25-A2701).

\section{REFERENCES}

Aasen I, Kolli L, Kumari V (2005). Sex effects in prepulse inhibition and facilitation of the acoustic startle response: implications for pharmacological and treatment studies. J Psychopharmacol 19: 39-45.

Abbas AI, Hedlund PB, Huang XP, Tran TB, Meltzer HY, Roth BL (2009). Amisulpride is a potent 5-HT7 antagonist: relevance for antidepressant actions in vivo. Psychopharmacology (Berl) 205: 119-128.

Aggernaes B, Glenthoj BY, Ebdrup BH, Rasmussen H, Lublin H, Oranje B (2010). Sensorimotor gating and habituation in antipsychotic-naive, first-episode schizophrenia patients before and after 6 months' treatment with quetiapine. Int J Neuropsychopharmacol 13: 1383-1395.

Arnfred SM, Chen AC, Glenthoj BY, Hemmingsen RP (2003). Normal p50 gating in unmedicated schizophrenia outpatients. Am J Psychiatry 160: 2236-2238.

Boutros NN, Zouridakis G, Overall J (1991). Replication and extension of P50 findings in schizophrenia. Clin Electroencephalogr 22: 40-45.

Braff D, Stone C, Callaway E, Geyer M, Glick I, Bali L (1978). Prestimulus effects on human startle reflex in normals and schizophrenics. Psychophysiology 15: 339-343.

Braff DL, Geyer MA, Swerdlow NR (2001). Human studies of prepulse inhibition of startle: normal subjects, patient groups, and pharmacological studies. Psychopharmacology (Berl) 156: 234-258. 
Braff DL, Light GA, Swerdlow NR (2007). Prepulse inhibition and P50 suppression are both deficient but not correlated in schizophrenia patients. Biol Psychiatry 61: 1204-1207.

Cadenhead KS, Geyer MA, Butler RW, Perry W, Sprock J, Braff DL (1997). Information processing deficits of schizophrenia patients: relationship to clinical ratings, gender and medication status. Schizophr Res 28: 51-62.

Csomor PA, Stadler RR, Feldon J, Yee BK, Geyer MA, Vollenweider FX (2008). Haloperidol differentially modulates prepulse inhibition and p50 suppression in healthy humans stratified for low and high gating levels. Neuropsychopharmacology 33: 497-512.

de Wilde OM, Bour LJ, Dingemans PM, Koelman JH, Linszen DH (2007). Failure to find P50 suppression deficits in young firstepisode patients with schizophrenia and clinically unaffected siblings. Schizophr Bull 33: 1319-1323.

Duncan E, Szilagyi S, Schwartz M, Kunzova A, Negi S, Efferen T et al (2003). Prepulse inhibition of acoustic startle in subjects with schizophrenia treated with olanzapine or haloperidol. Psychiatry Res 120: 1-12.

Hetrick WP, Sandman CA, Bunney WE Jr, Jin Y, Potkin SG, White MH (1996). Gender differences in gating of the auditory evoked potential in normal subjects. Biol Psychiatry 39: 51-58.

Horacek J, Bubenikova-Valesova V, Kopecek M, Palenicek T, Dockery C, Mohr P et al (2006). Mechanism of action of atypical antipsychotic drugs and the neurobiology of schizophrenia. CNS Drugs 20: 389-409.

Jensen KS, Oranje B, Wienberg M, Glenthoj BY (2007). The effects of increased central serotonergic activity on prepulse inhibition and habituation of the human startle response. Neuropsychopharmacology 32: 2117-2124.

Jensen KS, Oranje B, Wienberg M, Glenthoj BY (2008). The effects of increased serotonergic activity on human sensory gating and its neural generators. Psychopharmacology (Berl) 196: 631-641.

Kay SR, Opler LA, Lindenmayer JP (1988). Reliability and validity of the positive and negative syndrome scale for schizophrenics. Psychiatry Res 23: 99-110.

Kumari V (2011). Sex differences and hormonal influences in human sensorimotor gating: implications for schizophrenia. Curr Top Behav Neurosci 8: 141-154.

Kumari V, Aasen I, Sharma T (2004). Sex differences in prepulse inhibition deficits in chronic schizophrenia. Schizophr Res 69: 219-235.

Kumari V, Fannon D, Sumich AL, Sharma T (2007). Startle gating in antipsychotic-naive first episode schizophrenia patients: one ear is better than two. Psychiatry Res 151: 21-28.

Kumari V, Sharma T (2002). Effects of typical and atypical antipsychotics on prepulse inhibition in schizophrenia: a critical evaluation of current evidence and directions for future research. Psychopharmacology (Berl) 162: 97-101.

Kumari V, Soni W, Sharma T (2002). Prepulse inhibition of the startle response in risperidone-treated patients: comparison with typical antipsychotics. Schizophr Res 55: 139-146.

Ludewig K, Geyer MA, Vollenweider FX (2003). Deficits in prepulse inhibition and habituation in never-medicated, firstepisode schizophrenia. Biol Psychiatry 54: 121-128.

Mackeprang T, Kristiansen KT, Glenthoj BY (2002). Effects of antipsychotics on prepulse inhibition of the startle response in drug-naive schizophrenic patients. Biol Psychiatry 52: 863-873.

Natesan S, Reckless GE, Barlow KB, Nobrega JN, Kapur S (2008). Amisulpride the 'atypical' atypical antipsychotic-comparison to haloperidol, risperidone and clozapine. Schizophr Res 105: 224-235.

Nielsen MO, Rostrup E, Wulff S, Bak N, Broberg BV, Lublin H et al (2012a). Improvement of brain reward abnormalities by antipsychotic monotherapy in schizophrenia. Arch Gen Psychiatry 69: 1195-1204.

Nielsen MO, Rostrup E, Wulff S, Bak N, Lublin H, Kapur S et al (2012b). Alterations of the brain reward system in anti- psychotic naive schizophrenia patients. Biol Psychiatry 71: 898-905.

Oranje B, Aggernaes B, Rasmussen H, Ebdrup BH, Glenthoj BY (2013). P50 suppression and its neural generators in antipsychotic-naive first-episode schizophrenia before and after 6 months of quetiapine treatment. Schizophr Bull 39: 472-480.

Oranje B, Geyer MA, Bocker KB, Leon KJ, Verbaten MN (2006). Prepulse inhibition and P50 suppression: commonalities and dissociations. Psychiatry Res 143: 147-158.

Oranje B, Glenthoj BY (2013). Clonidine normalizes sensorimotor gating deficits in patients with schizophrenia on stable medication. Schizophr Bull. 39: 684-691.

Oranje B, van Berckel BN, Kemner C, van Ree JM, Kahn RS, Verbaten MN (1999). P50 suppression and prepulse inhibition of the startle reflex in humans: a correlational study. Biol Psychiatry 45: 883-890.

Oranje B, Van Oel CJ, Gispen-de Wied CC, Verbaten MN, Kahn RS (2002). Effects of typical and atypical antipsychotics on the prepulse inhibition of the startle reflex in patients with schizophrenia. J Clin Psychopharmacol 22: 359-365.

Perrault G, Depoortere R, Morel E, Sanger DJ, Scatton B (1997). Psychopharmacological profile of amisulpride: an antipsychotic drug with presynaptic D2/D3 dopamine receptor antagonist activity and limbic selectivity. J Pharmacol Exp Ther 280: 73-82.

Perry W, Feifel D, Minassian A, Bhattacharjie I, Braff DL (2002). Information processing deficits in acutely psychotic schizophrenia patients medicated and unmedicated at the time of admission. Am J Psychiatry 159: 1375-1381.

Quednow BB, Frommann I, Berning J, Kuhn KU, Maier W, Wagner M (2008). Impaired sensorimotor gating of the acoustic startle response in the prodrome of schizophrenia. Biol Psychiatry 64: 766-773.

Quednow BB, Wagner M, Westheide J, Beckmann K, Bliesener N, Maier W et al (2006). Sensorimotor gating and habituation of the startle response in schizophrenic patients randomly treated with amisulpride or olanzapine. Biol Psychiatry 59: 536-545.

Schoemaker H, Claustre Y, Fage D, Rouquier L, Chergui K, Curet O et al (1997). Neurochemical characteristics of amisulpride, an atypical dopamine D2/D3 receptor antagonist with both presynaptic and limbic selectivity. J Pharmacol Exp Ther 280: 83-97. Schwarzkopf SB, Lamberti JS, Smith DA (1993). Concurrent assessment of acoustic startle and auditory P50 evoked potential measures of sensory inhibition. Biol Psychiatry 33: 815-828.

Swerdlow NR, Sprock J, Light GA, Cadenhead K, Calkins ME, Dobie DJ et al (2007). Multi-site studies of acoustic startle and prepulse inhibition in humans: initial experience and methodological considerations based on studies by the Consortium on the Genetics of Schizophrenia. Schizophr Res 92: 237-251.

Turetsky BI, Calkins ME, Light GA, Olincy A, Radant AD, Swerdlow NR (2007). Neurophysiological endophenotypes of schizophrenia: the viability of selected candidate measures. Schizophr Bull 33: 69-94.

Volter C, Riedel M, Wostmann N, Aichert DS, Lobo S, Costa A et al (2012). Sensorimotor gating and D2 receptor signalling: evidence from a molecular genetic approach. Int J Neuropsychopharmacol 15: $1427-1440$.

Wienberg M, Glenthoj BY, Jensen KS, Oranje B (2010). A single high dose of escitalopram increases mismatch negativity without affecting processing negativity or P300 amplitude in healthy volunteers. J Psychopharmacol 24: 1183-1192.

Wing JK, Babor T, Brugha T, Burke J, Cooper JE, Giel R et al (1990). SCAN. Schedules for Clinical Assessment in Neuropsychiatry. Arch Gen Psychiatry 47: 589-593.

Wynn JK, Green MF, Sprock J, Light GA, Widmark C, Reist C et al (2007). Effects of olanzapine, risperidone and haloperidol on prepulse inhibition in schizophrenia patients: a double-blind, randomized controlled trial. Schizophr Res 95: 134-142. 